\title{
CMOS based thermal detector for processor
}

\author{
Lee Che Yang', Warsuzarina Mat Jubadi ${ }^{2}$ \\ ${ }^{1,2}$ Faculty of Electrical and Electronic Engineering, University Tun Hussein Onn Malaysia, Malaysia \\ ${ }^{2}$ Nano Simulation Research Group, Faculty of Electrical and Electronic Engineering, \\ University Tun Hussein Onn Malaysia, Malaysia
}

\begin{tabular}{|c|c|}
\hline Article Info & ABSTRACT \\
\hline Article history: & This project proposed a design of low power CMOS-based thermal detector \\
\hline Received Aug 20, 2019 & $\begin{array}{l}\text { which can detect the temperature of processor such as in Central Processing } \\
\text { Unit. By re-designing temperature detector circuit using CMOS technology, }\end{array}$ \\
\hline Revised Oct 21, 2019 & the reduction in power consumption and area size of the thermal detector can \\
\hline Accepted Nov 5, 2019 & $\begin{array}{l}\text { be obtained. In this paper, the design of thermal detector consists of } \\
\text { temperature sensing core, amplifier, and Analog to Digital Converter (ADC), }\end{array}$ \\
\hline Keywords: & $\begin{array}{l}\text { respectively. The sensor was designed using } 0.13 \mu \mathrm{m} \text { CMOS technology and } \\
\text { operates by sensing the temperature of processor and produced a digital }\end{array}$ \\
\hline CMOS & output value. The temperature detection range was setup between $0{ }^{\circ} \mathrm{C}$ to 80 \\
\hline Detector & ${ }^{\circ} \mathrm{C}$ with $10{ }^{\circ} \mathrm{C}$ resolution. The temperature detector was capable to show \\
\hline Flash ADC & temperature readings in binary value. It consumed an average power of 558.2 \\
\hline Temperature & $\mu \mathrm{W}$ and a space occupancy of $0.0118 \mathrm{~mm}^{2}$. \\
\hline
\end{tabular}

Copyright () 2020 Institute of Advanced Engineering and Science. All rights reserved.

\section{Corresponding Author:}

Warsuzarina Mat Jubadi,

Department of Electronic,

Faculty of Electrical and Electronics Engineering,

University Tun Hussein Onn Malaysia (UTHM),

Parit Raja, 86400 Batu Pahat, Johor, Malaysia.

Email: suzarina@uthm.edu.my

\section{INTRODUCTION}

Temperature sensor is commonly used for various kind of application such as in measurement, instrumentation, and control system [1-4]. Most of processors nowadays are easily overheated due to high usage of softwares and applications. Overheating of processor can cause system malfunction [5] and damage to the processor. Unfortunately, there is no warning showed when this problem happened. The damaged processor has to be replaced and it is quite costly to the user. Due to the high-power usage of the processor, it is even challenging to add-on the thermal sensor into the processor [6]. For an on-chip temperature sensors, it must be compatible with the technology available in the process, maintain a small area, has good accuracy with low power consumption over standard process variations and over typical supply voltage variations [1, 4, 6-7].

The Complementary Metal Oxide Semiconductor (CMOS) based thermal detector has been widely used because of the low power sensor characteristic. There are other different types of temperature sensors such as the Bipolar Junction Transistor (BJT) [7-9], graphene-based Field Effect Transistor (GFET) temperature sensor [10], resistor-based thermal sensor [11], and diode based temperature sensor [12-13]. In this project, the CMOS-based temperature sensor was selected because it consumes less power as compared to other types of temperature sensor. Nowadays, the minimum CMOS based thermal detector with $\mathrm{ADC}$ is needed to consume at least around $650 \mu \mathrm{W}$ [14]. By re-designing and lowering the number of transistors in the circuit, the power consumption of the CMOS based thermal detector can be reduced. In this paper, a low power consumption CMOS based thermal detector is designed using low power reduction techniques [15]. On the other hand, the circuit was designed to achieve small space occupancy and developed using Cadence software. The CMOS based thermal detector was aimed for the detection of temperature from 
$0{ }^{\circ} \mathrm{C}$ to $80{ }^{\circ} \mathrm{C}$; as the best performance of processor is within $27{ }^{\circ} \mathrm{C}$ (room temperature) to $60{ }^{\circ} \mathrm{C}$ [16]. The design parameter was optimized based on the objective to implement the sensor circuit for the detection of temperature in processor.

\section{CIRCUIT BLOCK DIAGRAM}

A temperature sensor is a device that provides the temperature measurement in electrical signal for example in the voltage form. The changes of the temperature cause the output voltage that produced by the temperature sensor to either increases or decreases. The electrical signal was then converted into digital form so that it can be shown in the other devices. Temperature sensors are easily produced with semiconductor processing technology by using the temperature characteristics of the PN junction [2-3]. The basic block diagram of CMOS based thermal detector is shown in Figure 1. The circuit design consist of a temperature sensing core, amplifier, and analogue to digital converter (ADC) sub-circuit.

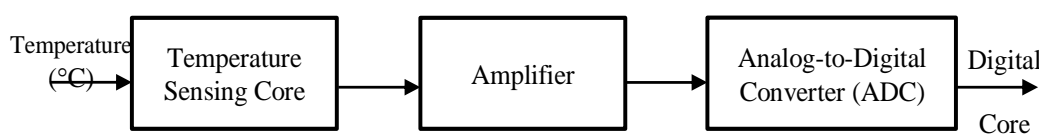

Figure 1. Basic block diagram of temperature sensor

\section{RESEARCH METHOD}

The sub-circuit for each block diagram in Figure 1 was designed in Cadence ${ }^{\circledR}$ custom/analog/RF using $0.13 \mu \mathrm{m}$ CMOS technology, which took the advantages of $\mathrm{P}$ - and $\mathrm{N}$ - channel of transistor device. The average value of power consumption for the whole circuit was measured by using the Analog Design Environment (ADE). The analysis of power consumption and space occupied space by the thermal detector was performed and compared with the performance of thermal detector circuit in previous work [4-5, 13-16].

\subsection{Temperature Sensing Core}

The temperature sensing circuit was developed based on self-stabilized feedback architecture [17]. A threshold-voltage, $\mathrm{V}_{\mathrm{T}}$ based is adapted where the circuit expresses temperature information as an output voltage. Figure 2(a) illustrates the current source circuit used in the design, which sets the threshold voltage. The current source sub-circuit is functioned as a self-biasing circuit that generates current which not affected by the voltage source. The current mirror circuit is formed by transistors M3 and M4. These transistors sizes determine the relationship between currents $I_{1}$ and $I_{2}$ of this current mirror circuit.

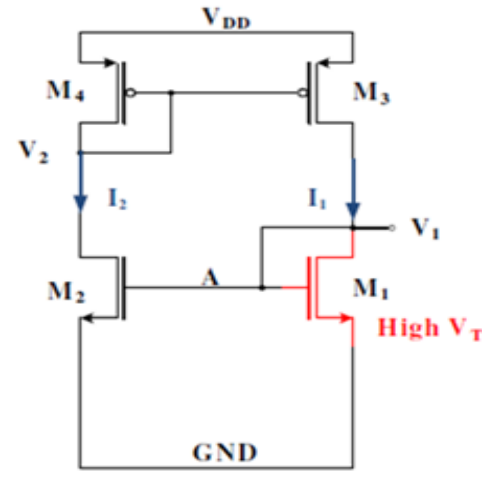

(a)

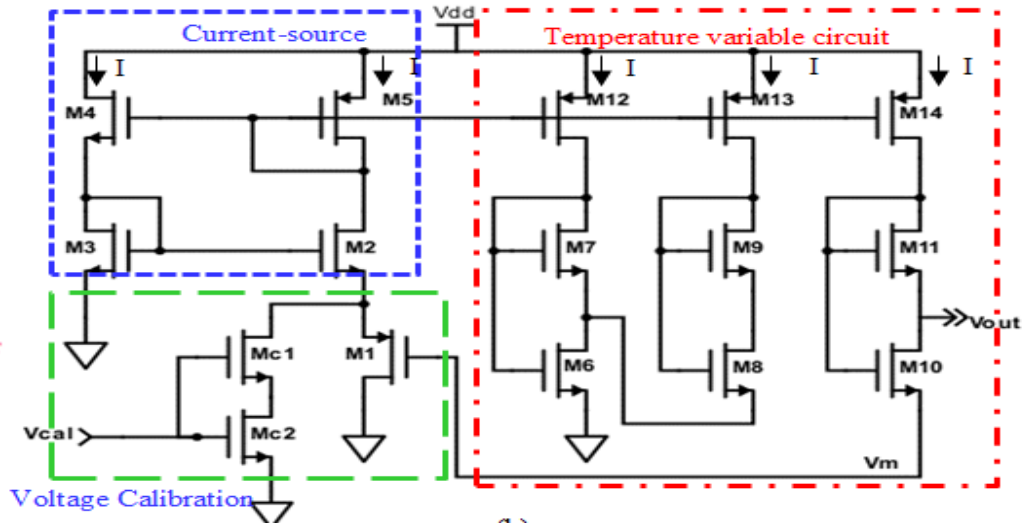

(b)

Figure 2. Schematic for (a) Current source circuit and (b) Temperature detector circuit

The circuit can be designed to operate with different current mirror gains and the mirror gain is a degree of freedom in the design space for these circuits [7]. The $\mathrm{V}_{\mathrm{T}}$-based temperature sensors can be 
described using the standard square-law device model. However, the channel length modulation effects is neglected. The design variables $\left\{\frac{W_{1}}{L_{1}}, \frac{W_{2}}{L_{2}}, \frac{W_{3}}{L_{3}}, \frac{W_{4}}{L_{4}}\right\}$ is obtained from (1) [18].

$$
\left\{\begin{array}{l}
\frac{1}{2} \mu_{n} C_{o x}\left(\frac{W}{L}\right)_{1}\left(V_{1}-V_{T_{1}}\right)^{2}=I_{1} \\
\frac{1}{2} \mu_{p} C_{o x}\left(\frac{W}{L}\right)_{3}\left(V_{D D}-V_{2}-\left|V_{T_{3}}\right|\right)^{2}=I_{1} \\
\frac{1}{2} \mu_{n} C_{o x}\left(\frac{W}{L}\right)_{2}\left(V_{1}-V_{T_{2}}\right)^{2}=I_{2} \\
\frac{1}{2} \mu_{p} C_{o x}\left(\frac{W}{L}\right)_{4}\left(V_{D D}-V_{2}-\left|V_{T_{4}}\right|\right)^{2}=I_{2}
\end{array}\right.
$$

The proposed temperature detector circuit is presented in Figure 2(b) which combines a current source circuit, temperature variable circuit, and voltage calibration circuit. The sensing circuit is combined with a flash ADC to perform the digital conversion. Table 1 tabulates the transistors size.

\begin{tabular}{ccc}
\multicolumn{3}{c}{ Table 1. Transistors Size in for Temperature Sensing Core } \\
\hline Transistor & No.of Fingers & Width/Length $(\mu \mathrm{m} / \mu \mathrm{m})$ \\
\hline M1 & 1 & $1.5 / 20$ \\
M2 & 10 & $3 / 3$ \\
M3 & 4 & $3 / 3$ \\
M6, M8, M10 & 1 & $1 / 3$ \\
M7 & 3 & $3 / 3$ \\
M9 & 4 & $3 / 3$ \\
M11 & 28 & $3 / 3$ \\
M4, M5 M12, M13, M14 & 1 & $3 / 10$ \\
MC1, MC2 & 1 & $1 / 20$ \\
\hline
\end{tabular}

\subsection{Amplifier Circuit}

A basic amplifier circuit operates like an inverter [1, 14]. It inverts the input voltage from high voltage to lower voltage and vice versa. The amplifier circuit in this work was design with a single PMOS and NMOS transistor. With the input voltage connected to the gate of NMOS transistor, while the gate of PMOS transistor connected to the output voltage, it acts as an op-amp that amplifies the voltage. A commonsource configuration was used in the circuit design.

\subsection{Analog to Digital Converter}

The most common types of ADC that are available in the market are the flash ADC, the successive approximation register (SAR) ADC and Sigma-delta ADC [19-21]. The flash ADC [22-23] uses comparator to compare the voltage differences between the input voltage and reference voltage. It has great conversion speed compared to SAR and Sigma-delta ADC. However, it consumes a lot of space since it requires many logic gates and voltage comparators [23]. Flash ADC is mostly used in conversion that required less than 8bit digital output. A SAR ADC [20] only requires one comparator and counting logic to perform the conversion. SAR ADC is normally used in which the value of output digital bits is not perfectly $2^{\mathrm{N}}$, where $\mathrm{N}$ is the number of bit [11]. The basic block diagram of a flash ADC applied in the design is shown in Figure 3.

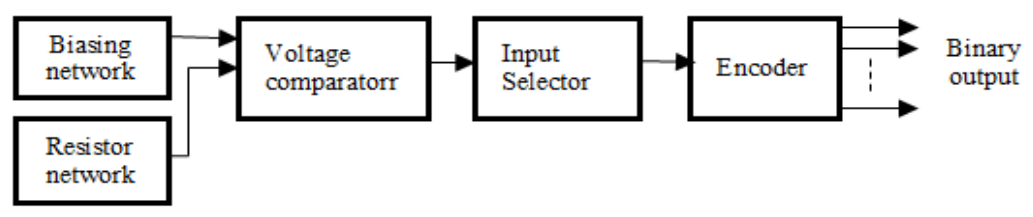

Figure 3. Block diagram of Flash ADC

The ADC block operates by comparing the input voltage with reference voltage. The output is shown in a digital form. All the output of the voltage comparators were sent to the selector circuit which determine whether the voltage obtained is within the specified range. The binary output of temperature readings were extracted using encoder circuit (OR gates). 


\section{RESULTS AND ANALYSIS}

\subsection{Temperature Sensing Core Output}

The input voltage for the temperature sensing core circuit is fixed at $1.2 \mathrm{~V}$. This is to make sure that the output voltage of the temperature sensing core is adequate to be used as the main input voltages for amplifier and ADC block. The length (L) of all the transistors is in the range of $3-20 \mu \mathrm{m}$. These transistor sizes were considered as to obtain a high resistance for better detection of temperature [17]. In practical, the temperature sensing core can be calibrated by measuring the die temperature (after fabrication) at a reference point. The temperature sensing core circuit occupies a space area of $0.00289 \mathrm{~mm}^{2}$ (or $120.9 \mu \mathrm{m} \times 23.9 \mu \mathrm{m}$ ) and consumes an average power of $1.045 \mu \mathrm{W}$. The gate-source voltage shows an exponential relationship with the drain current in the temperature variable sub-circuit as seen in Figure 4.

The output voltage was obtained by adding the gate-source voltage of the upper part transistors of the temperature sub-circuit and subtracting the voltage of the lower part transistors. This temperature sensing core was able to sense temperature in the range of $-260{ }^{\circ} \mathrm{C}$ to $170^{\circ} \mathrm{C}$. The temperature values were calibrated from 0 to $1.2 \mathrm{~V}$. At temperature $-260{ }^{\circ} \mathrm{C}$, the corresponding voltage was about $0.05 \mathrm{~V}$. Then, the voltage increased exponentially up to $170{ }^{\circ} \mathrm{C}$. Above this temperature value, the output voltage dropped drastically. This behavior was anticipated as $\mathrm{V}_{\mathrm{T}}$ is a temperature dependant parameter [19]. Thus, nonlinearity of the output voltage with respect to temperature is dominated by the $2^{\text {nd }}$ order temperature effects. The drastic falling trend above $170{ }^{\circ} \mathrm{C}$ might also introduced through the nonideal output conductance parameters in the transistor [18].

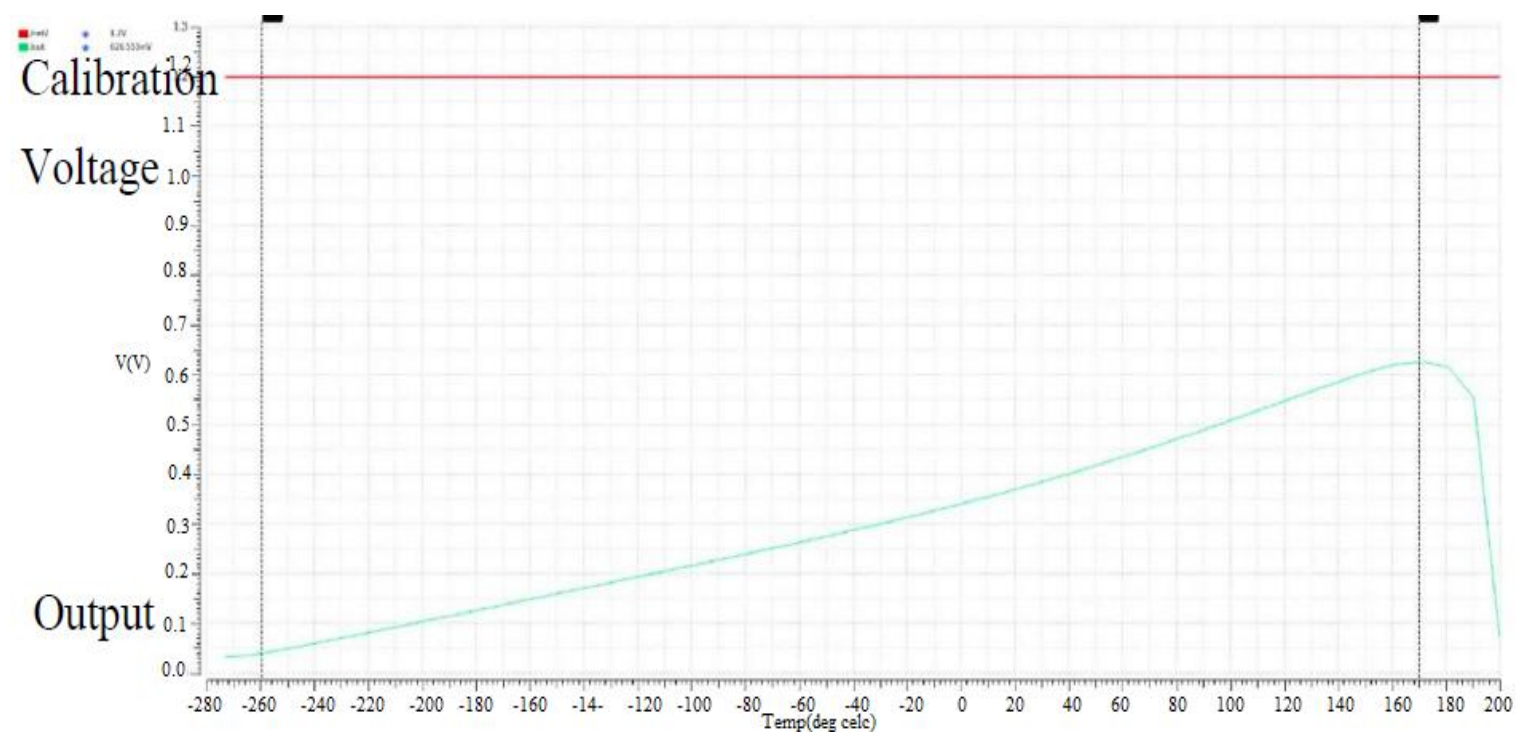

Figure 4. ADE of temperature sensing core

\subsection{Amplifier Output}

Figure 5 shows the output of the amplifier where the input is connected to the output of temperature sensing core. Therefore, amplifier circuit received a voltage input which represents the temperature values. The output voltage of the amplifier was about $744 \mathrm{mV}\left(\right.$ at $\left.0{ }^{\circ} \mathrm{C}\right)$ and $450 \mathrm{mV}\left(80^{\circ} \mathrm{C}\right)$, respectively. However, these readings were opposite the trend of the incoming input voltage obtained from the temperature sensing core, $341 \mathrm{mV}$ and $471 \mathrm{mV}$, respectively. This shows that the input voltage was inverted.

The output in Figure 5 was expected as the inverting amplifier amplifies and inverts the input signal. At $0{ }^{\circ} \mathrm{C}$, the input voltage was set as $340 \mathrm{mV}$ (obtained from temperature core circuit). The input voltage was proportionally increased about $10 \mathrm{mV}$ with every $5^{\circ} \mathrm{C}$ temperature value until it reached $470 \mathrm{mV}$ at $0{ }^{\circ} \mathrm{C}$. The output voltage was amplified about double the input voltage at low temperature and reduced as the temperature increased to $80^{\circ} \mathrm{C}$. The amplification gain $\left(\mathrm{A}_{\mathrm{V}}\right)$ was achieved by setup earlier made with transistor length parameter. The maximum output voltage was achieved by considering (2) [17].

$$
\operatorname{VOUT}(\max ) \cong \mathrm{V}_{\mathrm{DD}}-\left|\mathrm{V}_{\mathrm{T}}\right|
$$




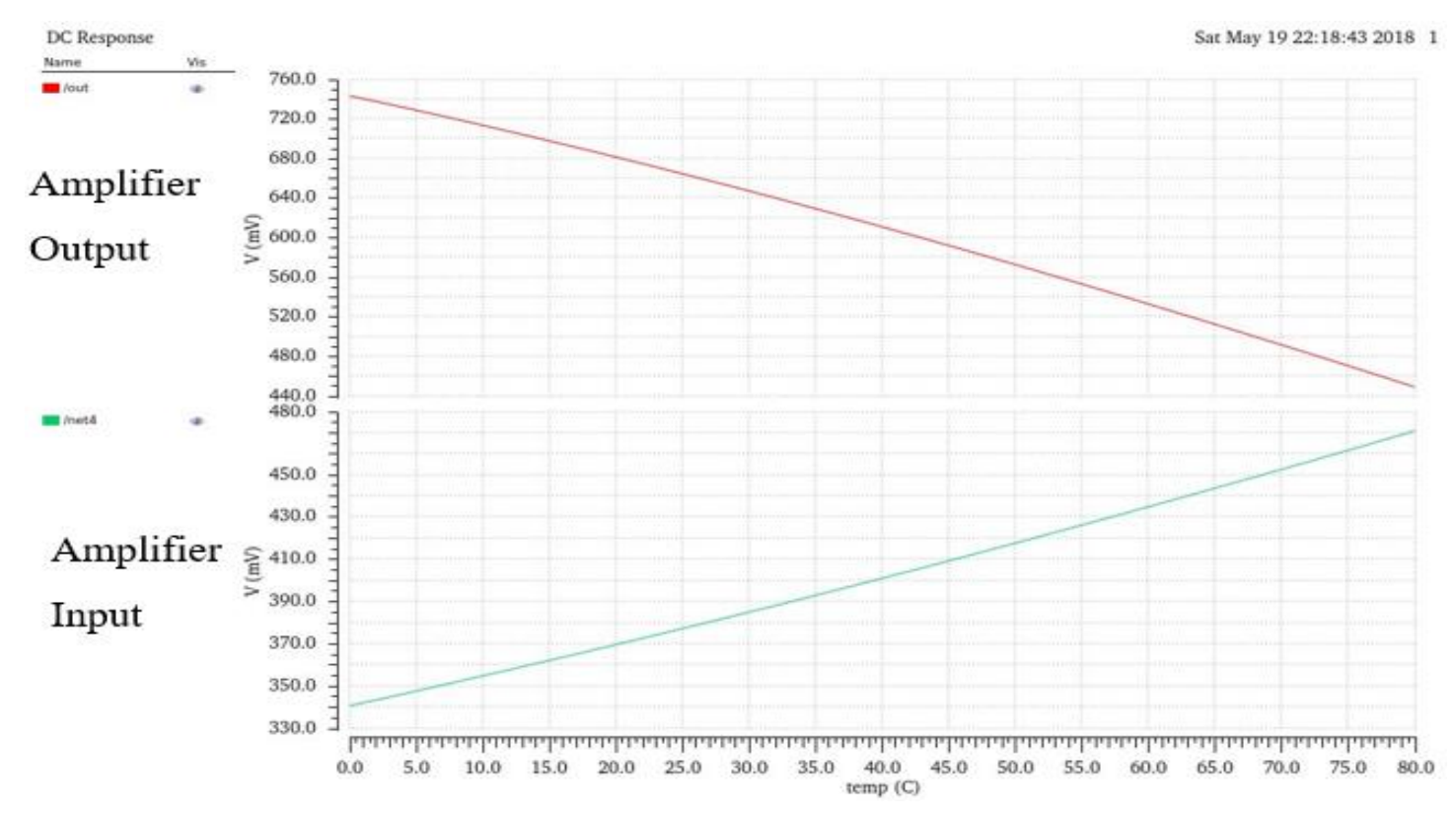

Figure 5. ADE of the amplifier connected to temperature sensing core

\subsection{Analog to Digital Converter (ADC) \\ 4.3.1 Resistor Network}

The resistor network in for ADC block in Figure 3 acta as an important role in providing reference voltages to the voltage comparators; which is compared with the input voltage. By having the output voltages and corresponding temperature based on temperature sensing output in Figure 5, the calculation of resistor values and corresponding voltages can be done according to (3) [19].

$$
V_{\text {ref }}=\frac{R_{a}}{R_{b}+R_{a}} \times V_{\text {in }}
$$

where $V_{r e f}$ is the reference voltage, $R_{a}$ is the total resistor value after the reference voltage, $R_{b}$ is the total resistor value before the reference voltage, and $V_{\text {in }}$ is the input voltage of set at $1.2 \mathrm{~V}$. The resistor value and corresponding voltage is shown in the Table 2.

Table 2. Resistor Value and Corresponding Voltage

\begin{tabular}{ccc}
\hline Resistor & Resistor Value $(\mathrm{k} \Omega)$ & Corresponding Voltage after resistor network $(\mathrm{V})$ \\
\hline R1 & 17.654 & 0.899 \\
R2 & 8.239 & 0.759 \\
R3 & 1.766 & 0.729 \\
R4 & 2.059 & 0.694 \\
R5 & 2.260 & 0.655 \\
R6 & 2.560 & 0.612 \\
R7 & 2.654 & 0.566 \\
R8 & 2.353 & 0.526 \\
R9 & 2.654 & 0.481 \\
R10 & 28.241 & 0.000 \\
R total & 70.440 & \\
\hline
\end{tabular}

\subsubsection{Voltage Comparator}

A voltage comparator circuit is sub-unit of a flash ADC circuit. It is used to compare the input voltage with the reference voltage (obtained from the resistor network). When the input voltage is higher than the reference voltage by approximately $400 \mathrm{mV}$, the voltage comparator gives an output of $40.8 \mathrm{mV}$. If the reference voltage is higher than the input voltage, the output voltage of $1.17 \mathrm{~V}$ is obtained. These results were plotted in Figure 6. If the $+V_{P}$, the input of the comparator is at a greater potential than the $-V_{N}$ input, the output of the comparator is a logic 1 . If the + input of comparator is at a potential less than the - input, the output of the comparator is at logic 0 . 


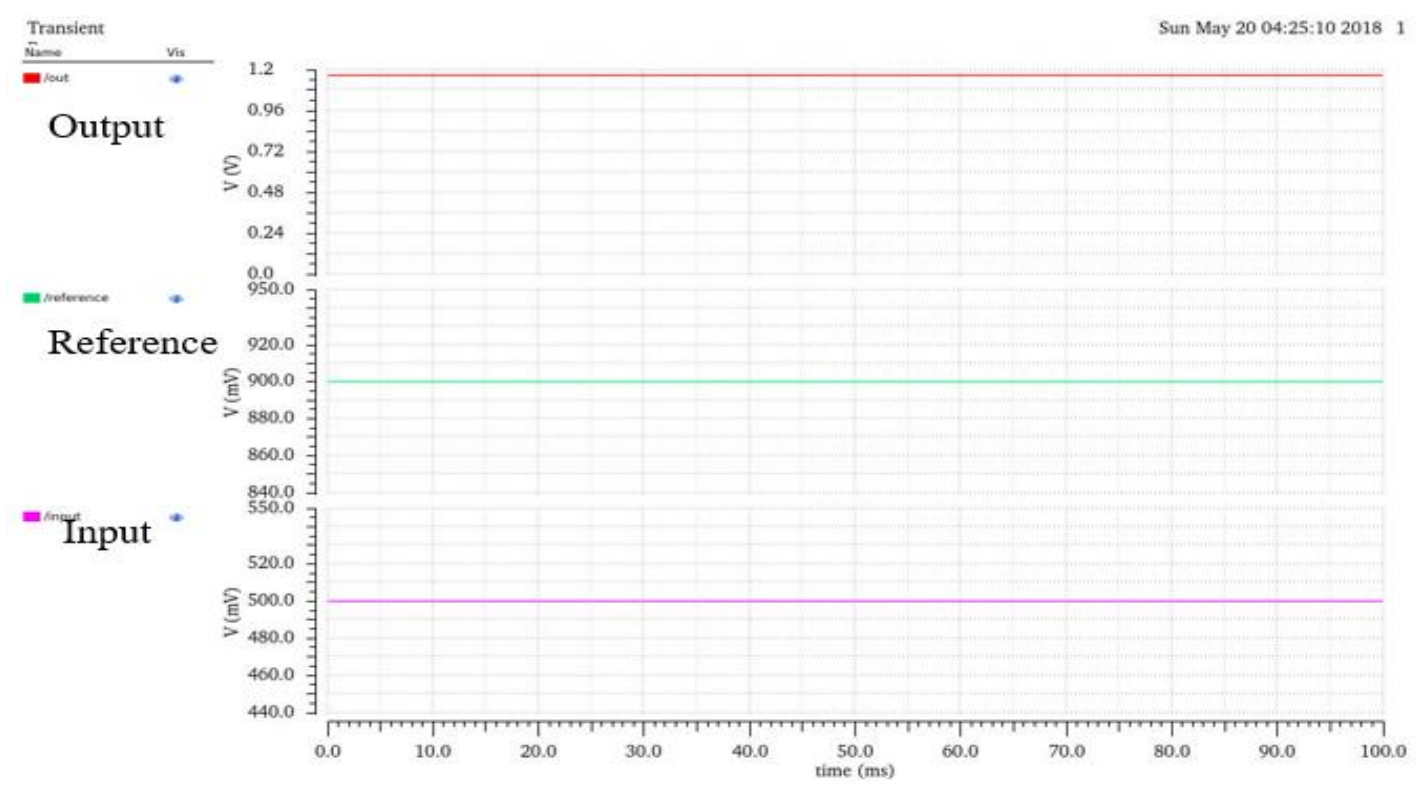

Figure 6. Output of Voltage Comparator when $\mathrm{V}_{\text {in }}<$ vref

\subsubsection{Digital Encoder Circuit}

The digital encoder circuit is developed using OR gates and implemented to combine the output from input selector circuit in order to show the binary output of the temperature detector. For the ADC circuit, a few different input OR gates were used, e.g., 2-input, 3-input, 5-input OR gate, etc. All those OR gates are designed to show the digital binary output of the ADC. The 2-input OR gate is used to show the $b 6$ bit, the 3-input OR gate was to show the $b 5$ bit, the 5-input OR gate was to show the $b 4$ bit, and another three 4-input OR gate was to show the output $b 3, b 2$ and $b 1$ bit. By combining the resistors, voltage comparator, XOR gates, and the OR gates, a full flash ADC circuit is developed.

\subsection{Complete Circuit}

After each block of the temperature sensing core, amplifier, and ADC circuit components have been designed, simulated, and verified; these blocks were combined to form the complete temperature detector circuit. This temperature detector circuit is capable to represent the temperature value $0{ }^{\circ} \mathrm{C}$ to $80^{\circ} \mathrm{C}$ as a 7 bit binary output as shown in Figure 7. Bit b6 is the most significant bit (MSB). This conversion was made possible with the ADC circuit. Figure 8 shows the overall circuit layout. Table 3 tabulates the results of temperature value and the binary output at a resolution of $10^{\circ} \mathrm{C}$.

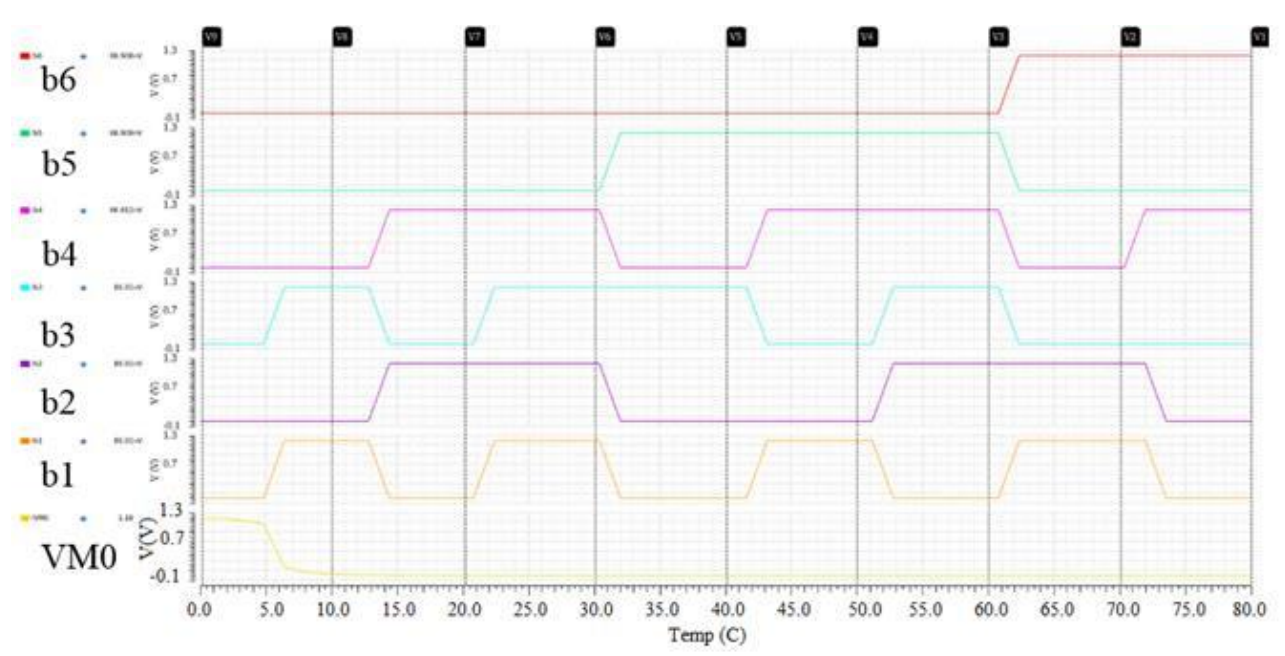

Figure 7. Binary Output View of ADC circuit 


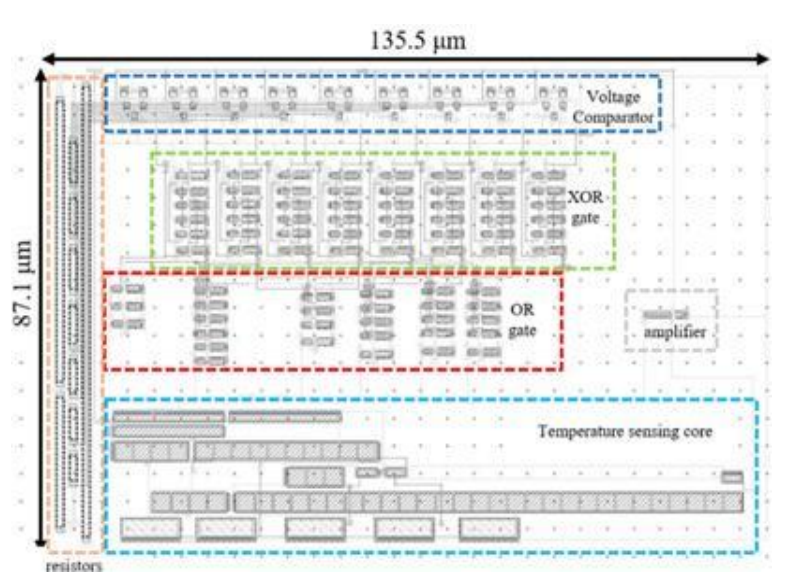

Table 3. Output of ADC Corresponding to Temperature

\begin{tabular}{cccccccc}
\hline $\begin{array}{c}\text { Temperature } \\
\left({ }^{\circ} \mathrm{C}\right)\end{array}$ & \multicolumn{7}{c}{ Binary Output of ADC } \\
\cline { 2 - 7 } 0 & $\mathrm{~b} 6$ & $\mathrm{~b} 5$ & $\mathrm{~b} 4$ & $\mathrm{~b} 3$ & $\mathrm{~b} 2$ & $\mathrm{~b} 1$ & $\mathrm{VM}$ \\
10 & 0 & 0 & 0 & 0 & 0 & 0 & 1 \\
20 & 0 & 0 & 0 & 1 & 0 & 1 & 0 \\
30 & 0 & 0 & 1 & 0 & 1 & 0 & 0 \\
40 & 0 & 0 & 1 & 1 & 1 & 1 & 0 \\
50 & 0 & 1 & 0 & 1 & 0 & 0 & 0 \\
60 & 0 & 1 & 1 & 0 & 0 & 1 & 0 \\
70 & 0 & 1 & 1 & 1 & 1 & 0 & 0 \\
80 & 1 & 0 & 0 & 0 & 1 & 1 & 0 \\
\hline
\end{tabular}

Figure 8. Layout View of Full Temperature Detector $(135.5 \mu \mathrm{m} \times 87.1 \mu \mathrm{m})$

\section{CONCLUSION}

Overall, the temperature detector to detect the temperature range from $0{ }^{\circ} \mathrm{C}$ to $80{ }^{\circ} \mathrm{C}$ with the resolution of $10{ }^{\circ} \mathrm{C}$ has been successfully designed. The temperature detector also has a low power consumption of $558.2 \mu \mathrm{W}$ with space occupancy of $0.0118 \mathrm{~mm}^{2}$. The power dissipation is expected to be higher than other previous work [14, 17, 23-25]. This is due to the existing of flash ADC that contains nine units of voltage comparators (about $60 \mu \mathrm{W}$ each). On the plus side, this temperature detector design is capable to show the temperature in binary value which not offered in most of other works in $[23-4,6]$. Compared to the CMOS temperature sensor with built-in ADC [14], this work has lower power consumption by $14 \%$ with a reduction of about $91.8 \mu \mathrm{W}$. For more accurate temperature reading, the resolution of the temperature detector can be increased by modifying the voltage comparator design to be more precised in comparing voltage. However, the complexity of circuit is also predictable due to additional of gates operation and layout size increases.

\section{ACKNOWLEDGEMENTS}

The authors would like to thanks University Tun Hussein Onn Malaysia for the research facilities and financial support under TIER 1 grant (Grant scheme: H216).

\section{REFERENCES}

[1] M. A. P. Pertijs and J. H. Huijsing, Precision Temperature Sensor in CMOS Technology. Springer, 2006.

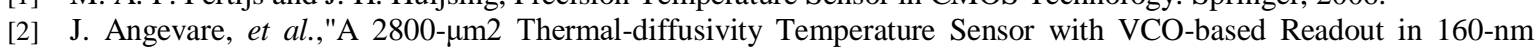
CMOS," 2015 IEEE Asian Solid-State Circuits Conference (A-SSCC), Xiamen,pp. 1-4, 2015.

[3] M. Law, et al.,"A $1.1 \mu \mathrm{W}$ CMOS Smart Temperature Sensor With an Inaccuracy of $\pm 0.2{ }^{\circ} \mathrm{C}(3 \sigma)$ for Clinical Temperature Monitoring," IEEE Sensors Journal, vol. 16, no. 8, pp. 2272-2281, April 15, 2016.

[4] S. S. Chouhan and K. Halonen, "A CMOS based $\mu$-power Smart Temperature Sensor for ON-chip Thermal Monitoring," 2014 IEEE 57th International Midwest Symposium on Circuits and Systems (MWSCAS), College Station, TX, pp. 382-385, 2014.

[5] C. M. Velpula, Jayant and V. Shahi, "CPU temperature aware scheduler a study on incorporating temperature data for CPU scheduling decisions," 2015 International Conference on Advances in Computing, Communications and Informatics (ICACCI), Kochi, pp. 2409-2413, 2015.

[6] Y. Yu and C. Wu, "Designing a Temperature Model to Understand the Thermal Challenges of Portable Computing Platforms," 2018 17th IEEE Intersociety Conference on Thermal and Thermomechanical Phenomena in Electronic Systems (ITherm), San Diego, CA, 2018, pp. 992-999, 2018.

[7] G. Wang, et al.,"An Accurate BJT-Based CMOS Temperature Sensor with Duty-Cycle-Modulated Output," IEEE Trans. Ind. Electron., vol. 64, no. 2, pp. 1572-1580, 2017.

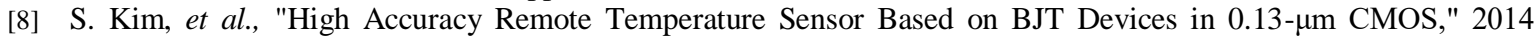
International Symposium on Integrated Circuits (ISIC), Singapore, 2014, pp. 408-411,2014.

[9] T. Oshita, et al., "Compact BJT-Based Thermal Sensor for Processor Applications in a $14 \mathrm{~nm}$ tri-Gate CMOS Process," IEEE Journal of Solid-State Circuits, vol. 50, no. 3, pp. 799-807, March 2015.

[10] L. Vicarelli et al., "Graphene Field Effect Transistors as Room-temperature Terahertz Detectors," Nat. Mater., vol. 11, no. 10, pp. 865-871, 2012. 
[11] A. Mordakhay and J. Shor, "Miniaturized, $0.01 \mathrm{~mm} 2$, Resistor-Based Thermal Sensor With an Energy Consumption of $0.9 \mathrm{~nJ}$ and a Conversion Time of $80 \mu$ s for Processor Applications," IEEE Journal of Solid-State Circuits, vol. 53, no. 10, pp. 2958-2969, Oct. 2018.

[12] S. Rao, et al., "Temperature sensor based on 4H-SiC diodes for hostile environments," 2015 XVIII AISEM Annual Conference, Trento, pp. 1-4, 2015.

[13] M. de Souza, M. A. Pavanello and D. Flandre, "Low power highly linear temperature sensor based on SOI lateral PIN diodes," 2016 IEEE SOI-3D-Subthreshold Microelectronics Technology Unified Conference (S3S), pp. 1-3, 2016.

[14] P. R. Thota and A. K. Mal, "CMOS Temperature Sensor with Built-in ADC," 2016 International Conference on Microelectronics, Computing and Communications (MicroCom), Durgapur, 2016, pp. 1-6, 2016.

[15] S. Jeong et al., "A Fully-Integrated $71 \mathrm{nW}$ CMOS Temperature Sensor for Low Power Wireless Sensor Nodes," IEEE J. Solid-State Circuits, vol. 49, no. 8, pp. 1682-1693, 2014.

[16] Rudy J. van de Plassche, CMOS Integrated Analog-to-Digital and Digital-to-Analog Converters. $2^{\text {nd }}$ Edition. Springer, 2013.

[17] A. Sahafi, et al.,"Nano Watt CMOS Temperature Sensor," Analog Integr. Circuits Signal Process, vol. 75, no. 3, pp. 343-348, 2013.

[18] C. Zhao, "CMOS on-chip temperature sensors for power management," Iowa State University, PhD Thesis, 2014.

[19] N. Jandhyala, et al., "CMOS based low cost Temperature Sensor," 9th Int. Symp. Qual. Electron. Des., pp. 293-296, 2008.

[20] F. Makara, et al., "A 34fJ/conversion-step 10-bit 6.66MS/s SAR ADC with Built-in Digital Calibration in 130nm CMOS," 2017 30th Symposium on Integrated Circuits and Systems Design (SBCCI), Fortaleza, pp. 180-184, 2017.

[21] K. L. Krishna, et al.,"A IV Second Order Delta Sigma ADC in 130nm CMOS," International Conference on Information Communication and Embedded Systems (ICICES2014), Chennai, 2014, pp. 1-5, 2014

[22] K. M. C. Babu and P. A. H. Vardhini, "A 30mW, $2.5 \mathrm{Gs} / \mathrm{S}$ Flash Analog to Digital Converter in 0.13 $\mu \mathrm{m}$ CMOS TSMC technology," 2016 International Conference on Electrical, Electronics, and Optimization Techniques (ICEEOT), pp. 3291-3295, 2016.

[23] P. Chen, et al., "A Time-to-Digital-Converter-Based CMOS Smart Temperature Sensor,” IEEE Jounal Solid-state Circuits, vol. 40, no. 8, pp. 1642-1648, 2005.

[24] M. Jalalifar and B. Gyung-su, "A Wide Range CMOS Temperature Sensor With Process Variation Compensation for On-Chip Monitoring,” IEEE Sensor Journal, vol. 16, no. 14, pp. 5536-5542, 2016.

[25] S. Ann, et al., "Design of $0.35 \mu \mathrm{m}$ CMOS Temperature Sensor for Automatic Refresh Cycle in DRAM Memory Cell,” IEEE Eur. Model. Symp., pp. 446-449, 2015.

\section{BIOGRAPHIES OF AUTHORS}

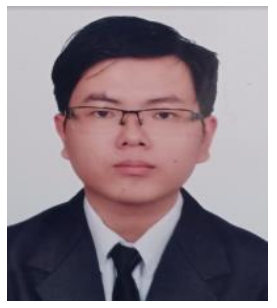

Lee, Che Yang was born in the city of Seremban, Negeri Sembilan, Malaysia in 1994. He received his Bachelor's degree in Electronic Engineering from the Universiti Tun Hussein Onn Malaysia, Johor, Malaysia in 2018. Currently, he is working as a pre-silicon validation engineer in Intel, Pulau Pinang, Malaysia.

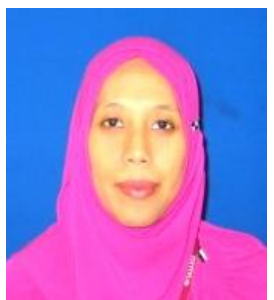

Warsuzarina Mat Jubadi obtained B. Eng in Electrical and Electronic Engineering and M. Eng in Electronic Telecommunications, respectively in 2001 and 2006 from University Teknologi Malaysia, Malaysia. In 2015, she received her Ph.D. in Electrical and Electronics Engineering from The University of Manchester, United Kingdom. She is a senior lecturer at the Faculty of Electrical and Electronic Engineering, University Tun Hussein Onn Malaysia, Malaysia. Her current research interests include analog and digital system design, device modelling and simulation of high RF and low power devices based on silicon and compound semiconductor materials 